Türkiye Tarımsal Araştırmalar Dergisi
http://dergi.siirt.edu.tr/index.php/ziraat $\begin{aligned} & \text { Turk J Agric Res } \\ & \text { (2014) 1: 203-212 } \\ & \text { TÜTAD } \\ & \text { ISSN: 2148-2306 }\end{aligned}$

\title{
Işık ve Sıcaklığın Bağcılıktaki Yeri ve Önemi
}

\author{
Bülent KÖSE* \\ Ondokuz Mayıs Üniversitesi, Ziraat Fakültesi, Bahçe Bitkileri Bölümü, Samsun, TÜRKIYYE
}

\begin{abstract}
Geliş Tarihi/Received: 09.07.2014
Kabul Tarihi/Accepted: 25.07.2014

"Sorumlu Yazar/Correspondence: bulentk@omu.edu.tr

Özet: Asmanın gelişimi üzerine etkili iklim faktörlerinin başında ışık ve sıcaklık gelmektedir. Işıı ve sıcaklık asmada fotosentez, solunum, asimilasyon, transpirasyon, renk pigmentlerinin oluşumu, gölgelenme, tane tutumu, asitlik, verimlilik, çiçeklenme, suda çözünebilir kuru madde birikimi, sürgün gelişimi ve olgunluk üzerine doğrudan etki etmektedir. Sıcaklık bir bölgede ekonomik anlamda bağcılık yapılıp yapılamayacă̆ını belirleyen en önemli parametrelerden biridir. Sıcaklık; asmada gözlerin uyanması, çiçeklenme, tane tutumu, renklenme, fotosentez, solunum, tanede şeker birikimi ve olgunlaşma gibi birçok fizyolojik olayı yönetmektedir. Işık, fotosentez başta olmak üzere pek çok fizyolojik ve kimyasal olayların gerçekleşmesinde önemli rol oynamaktadır. Özellikle asmanın maksimum düzeyde fotosentez yapabilmesi için vejetasyon döneminde yeterli bir güneşlenme şarttır. Işık, karbondioksit $\left(\mathrm{CO}_{2}\right)$ ve öteki etmenler sinırlayıcı olmamak şartıyla fotosentezi bir noktaya kadar arttırmaktadır. Işık miktarının azlığı kadar yüksekliği de, bitkinin gelişimi üzerine olumsuz etkide bulunabilmektedir. Düşük 1şık sürgünlerde c1lız gelişmeye neden olurken, yüksek 1șık yoğunluğu klorofil yıkımı sonucu fotosentezi engellemektedir. Bağlarda en üst düzeyde güneşlenmeyi sağlayabilmek için uygun terbiye sistemi seçimine ve sürgün sıklığının ayarlanmasına dikkat edilmelidir.
\end{abstract}

Anahtar Kelimeler: Işık, sıcaklık, asma, büyüme, gelişme, fotosentez

\section{The Role and Importance of the Light and Temperature in Viticulture}

Abstract: The light and temperature come at the beginning of the climatic factors that have an impact on the development of grapevine. Light and temperature have a direct impact on photosynthesis, respiration, assimilation, transpration, formation of color pigments, shading, berry set, acidity, productivity, shoot growth, blooming, soluble solid accummulation and maturation on the grapevine. Temperature is one of the most important parameters that determines whether viticulture can be made or not in an ecology. Temperature is driving several physiological processes such as bud burst, flowering, berry set, colorization, photosynthesis, respiration, sugar accimilation and ripening. In particular, in order to carry out maximum photosynthesis of vine should be sufficient sunshine in the vegetation period. On condition that carbon dioxide and other factors not be limitting, the light increases the photosynthesis up to a certain point. Not only the limited amount of the light, but also the excess of light intensity may have an adverse impact on the development of the plant. While low light causes poor development in the shoots, high light intensity prevents the photosynthesis as a result of chlorophyll degradation. In the vineyards to ensure the highest level of sunshine should be attention to the selection of appropriate training systems and canopy management.

Keywords: Light, temperature, grapevine, growth, development, photosynthesis

\section{Giriş}

Üzüm, farklı değerlendirme şekilleri sayesinde, dünya üzerinde kültürü yapılan en eski meyve türlerinden biri olmuştur. $\mathrm{Bu}$ sayede bağcılık yüzyıllardır insanların beslenmesinde ve geçimleri sağlamalarında önemli bir yer tutmaktadır. Bağcılık tarihinin M.Ö. 6000'li yıllara kadar dayandığı belirtilmektedir (Ağaoğlu, 1999). Tüm dünyada yaklaşı 40 ülkede (Tonietto ve Carbonneau, 2004), 6.969.373 hektar alanda, 67.067.129 ton üzüm üretimi yapılmaktadır 
(Anonymous, 2014). Dünyada en fazla çeşide sahip olan türlerden biri olan asmanın 15.000 kadar çeşidi olduğu tahmin edilmektedir (Alleweldt, 1997).

Asma, sıcak-1lıman iklim bölgelerinin bitkisi olmasına karşın, yüksek adaptasyon yeteneğinden dolayı daha serin veya daha sicak iklimlerde de yetiştirilebilmektedir. Ekonomik anlamda bir üretim için iklim koşullarının önemi büyüktür. Ekolojik faktörler (iklim, yer, yöney, enlem derecesi vb.) asmanın büyüme ve gelişmesi üzerine oldukça etkide bulunmaktadır (Happ, 1999). İklimi oluşturan etmenlerden sicaklık ve güneşlenme süresi asmada büyüme, gelişme, çiçeklenme, tane tutumu, olgunlaşma ve üzümün kalitesini etkilemektedir (Van Leeuwen ve ark., 2004). Asmada optimum fotosentez etkinliği için sıcaklığın 20-30 ${ }^{\circ} \mathrm{C}$ arasında olması (Hunter ve Bonnard, 2011), üzümlerin olgunlaşmasında yıllık güneşlenme süresinin ise 1300 saatin altında olmaması gerektiği (Oraman, 1970) bildirilmektedir.

Cartechini ve Palliotti (1995), asma bitkisinin 1şık yoğunluğundaki değişikliğe adapte olabildiğini ve belli miktarlarda karbonhidrat üretebildiğini belirtmiştir. Bağcılıkta kullanılan iklim parametrelerinden biri olan Branas Heliotermal İndeksi (BHI), güneş 1şı̆̆ yönünden bağ bölgelerinin değerlendirilmesinde, çeşit adaptasyonu, terroir, fonolojik gelişme ve olgunlaşma özelliklerinin belirlenmesinde kullanılmaktadır (Blanco-Ward ve ark., 2007; Irimia ve ark., 2013).

Bu derlemede, önemli iklim faktörlerinden olan 1şık ve sıcaklığın ilgili literatürler ışığında bağcılık ve asmanın fizyolojisi açısından yeri ve önemini ortaya koymak amaçlanmıştır.

\section{Sıcaklığın Bağcılık Üzerine Etkisi}

Bağcılıkta ekolojik faktörler, özellikle de iklim belirleyici rol oynamaktadır (Öndeş ve ark., 2005). İklimi oluşturan özelliklerden biri olan sıcaklık, bir ekolojide bağcılık yapılıp yapılamayacağını belirleyen en önemli parametrelerden biridir. Herhangi bir ekolojide ideal bir üzüm yetiştiriciliği için yıllık ortalama sıcaklığın $10{ }^{\circ} \mathrm{C}$ 'nin, gelişme dönemindeki sıcaklığın da $18{ }^{\circ} \mathrm{C}$ 'nin altına düşmemesi gerekmektedir (Çelik, 2007). Yine vejetasyon döneminde sicaklığın $10^{\circ} \mathrm{C}$ 'nin altına düşmesi veya $35^{\circ} \mathrm{C}$ 'nin üzerine çıkması asmanın gelişimini olumsuz yönde etkilemektedir (Happ, 1999). Dünyada bağcilık $30^{\circ}-50^{\circ}$ kuzey, $30^{\circ}-40^{\circ}$ güney enlem dereceleri ve ortalama $12-24{ }^{\circ} \mathrm{C}$ sıcaklık değerleri arasında (kuzey yarım kürede Nisan-Ekim, güney yarım kürede Ekim-Nisan ayları arasında) yayılım göstermektedir (Şekil 1).

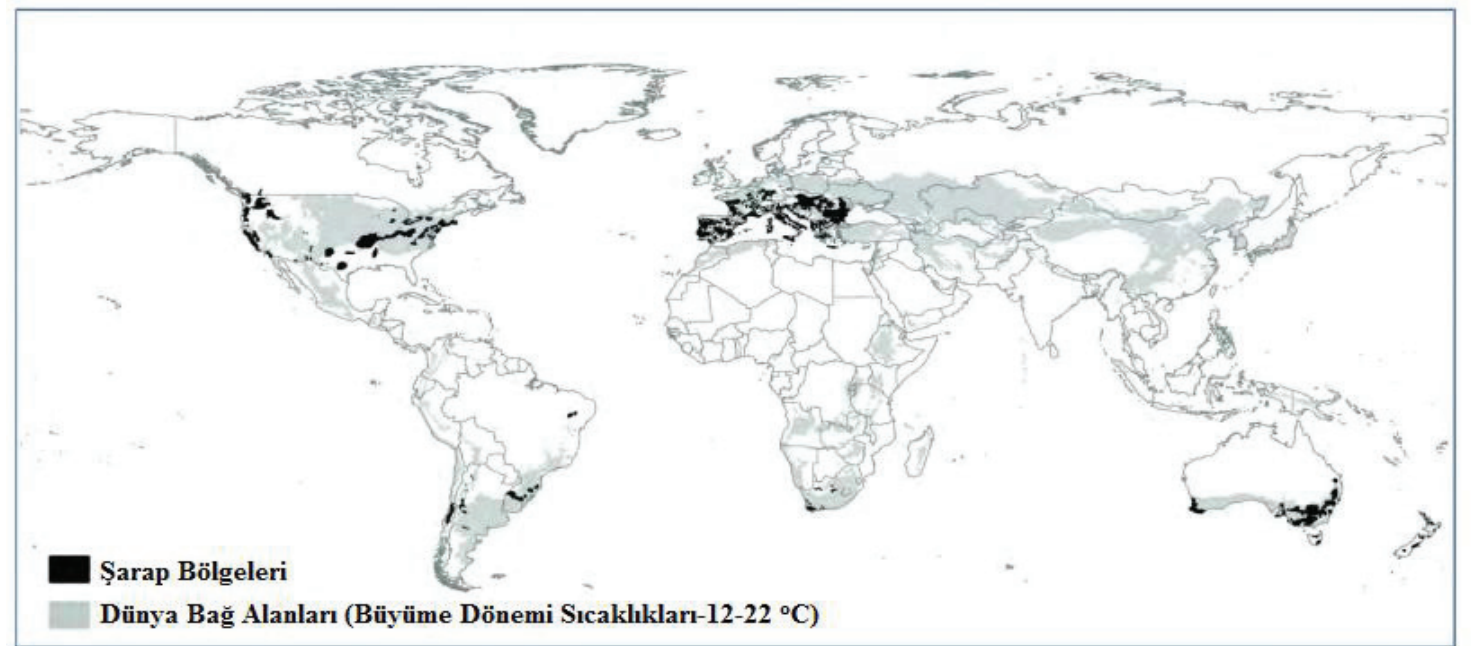

Şekil 1. Dünya'da bağcılığın yoğun olarak yapıldığı bölgelerin dağılımı (Jones ve ark., 2012) 
İklim parametreleri kullanılarak bağ bölgelerinin iklim yapısı ve uygunluğun belirlenmesi amacıyla iklim indeksleri geliştirilmiştir. Bağcılık potansiyelinin belirlenmesinde en yaygın olarak Winkler ve Huglin indekslerinden istifade edilmektedir (Amerine ve Winkler, 1944; Huglin, 1978). Winkler indeksi, "Etkili Sicaklık Toplamı (EST)" olarak da bilinmekte ve $10{ }^{\circ} \mathrm{C}$ 'nin üzerindeki sicaklıkların toplamı EST olarak ifade edilmektedir. $\mathrm{Bu}$ hesaplamada kuzey yarım kürenin bağcılık kuşağ1 için 1 Nisan-31 Ekim tarihleri arasındaki değerler esas alınır. Bağcılığa elverişli etkili sıcaklık toplamının alt sınırının 900, üst sınırının 2700 gün-derece olduğu bildirilmiştir (Amerine ve Winkler, 1944; Schwartz, 2003). Huglin indeksi, vejetasyon devresi boyunca (1 Nisan-31 Ekim), ortalama günlük sıcaklıklardan $10{ }^{\circ} \mathrm{C}$ 'nin çıkarılmasıyla elde edilen değerlerin, gün uzunluğu katsayısı ( $d$ : 1.04 Kuzey yarım küre için) ile çarpılmasıyla elde edilen değerlerin toplamını ifade etmektedir. Bağcılık için Huglin İndeksi (IH) 1500'den aşağı olmamalıdır (Huglin, 1978; Tonietto ve Carbonneau, 2004; Çelik, 2007).

Sıcaklığın sürgün gelişimi ve meyve kalitesi üzerinde önemli bir etkisi vardır. Sıcaklık asmada büyüme hızını ve yaprak alanı gelişimini yöneten önemli iklim faktörlerinden birisidir (Lebon ve ark., 2006). Asmada sürgünlerin büyümesi ve bitki tacının gelişimi çevre koşullarından oldukça etkilenmektedir. Asmada optimum fotosentez için 25-35 ${ }^{\circ} \mathrm{C}$ derece arasında sıcaklığa ihtiyaç duyulduğu bildirilmiştir (Kriedemann, 1968). Bununla birlikte, yüksek sicaklıların $\left(>35{ }^{\circ} \mathrm{C}\right)$ fotosentezin azalmasıla birlikte sürgün büyümesini azalttığ1, şeker birikiminin ve depolanmasının ve asit yıkım hızının azalmasına yol açtığ 1 (Ferrini ve ark., 1995), direk güneş 1 şı ğ1 alarak çevresinden daha yüksek sıcaklıklara maruz kalan salkımlarda ise meyve olgunlaşması ve renk gelişiminin durmasına ya da gerilemesine yol açtığ

Büyüme sezonundaki sicaklıklar üzüm kalitesini ve yapısını en az üç yolla etkileyebilmektedir. İlk olarak, $10{ }^{\circ} \mathrm{C}$ üzerindeki uzun süreli sıcaklıklar ilkbaharda vejetatif büyümeyi başlatarak büyüme döneminin başlangıcını belirler. İkinci olarak çiçeklenme ve tane gelişimi boyunca ekstrem sıcaklıklar erken ben düşmeye, enzimlerin inaktivasyonuna ve olgunluktaki lezzet kayıplarına yol açabilir (Mullins ve ark., 1992). Üçüncü olarak, olgunlaşma döneminde gerçekleşen yüksek günlük sicaklıklar, tanenler, şekerler ve aroma maddelerinin sentezinin artmasina yol açabilmektedir (Gladstones, 1992).
Işık gibi sıcaklık da gün boyunca değişir ve bitkiler günün önemli bir kısmını fotosentez için gerekli olan optimum sıcaklığın altındaki veya üstündeki sicaklıklarda geçirirler. Işık, karbondioksit ve öteki etmenler sınırlayıcı olmamak şartıyla belli bir düzeye kadar sıcaklık artışı fotosentezi de artırmaktadır. Ilıman iklim bölgelerinde yetişen bitkilerin çoğunda fotosentez için uygun sıcaklıkların 20-30 ${ }^{\circ} \mathrm{C}$ arasında olduğu bildirilmiştir (Kacar, 1989). Bitkilerdeki fizyolojik olayların birçoğunun karbonhidratlarla ilişkisi vardır. Bitkide fotosentezle üretilen, depo edilen ve çeşitli olaylarda kullanılan en önemli maddeler karbonhidratlardır (Eriş, 1990). Düşük sicakliklarda fotosentez genellikle kloroplastlardaki fosfatın kullanılabilirliği ile sınırlanmaktadır. Sicaklık artıșı trioz fosfata olan gereksinimi düşürerek nişasta ve şeker sentezini hızla azalttığı (Akman ve ark., 2000), sıcaklığın aşırı derecede yükselmesi veya azalmasının da asmada fotosentezi ve stomatal dayanımı azalttığ1 belirtilmiştir (During, 1994).

\subsection{Sıcaklığın salkım ve tane içeriği üzerine etkisi}

Sıcaklık tane gelişimini etkilemektedir. Yüksek sıcaklıklar çiçeklenmeyi etkileyerek ürün kaybına neden olabilmekte, sezon sonunda tane büyümesinin yavaşlamasına ve şeker birikiminin azalmasına, hasadın gecikmesine sebep olmaktadır (Greer ve Weston, 2010). Kontrollü şartlar altına yapılan çalışmalar göstermiştir ki, tane büyüme hızı 1şık arttığında artmaktadır (Dookozlian ve Kliewer, 1996). Bu durumun 1şı̆̆ı̀n hücre bölünmesini ve büyümesini tetiklemesiyle oluştuğu öngörülmektedir. Bunun yanı sıra sıcaklık da hem hücre bölünmesini hem de hücre büyümesini etkilemektedir. Tane büyümesi için optimum sicaklık sicaklıklar 20-25 ${ }^{\circ} \mathrm{C}$ iken, 35 ${ }^{\circ} \mathrm{C}$ 'nin üzerindeki sicaklıklarda tane büyümesi ve iriliği azalmaktadır (Dookozlian, 2000). Ancak, Soar ve ark. (2009), Shiraz üzüm çeşidinde asmanın tacı içerisindeki sıcaklığının $40 \quad{ }^{\circ} \mathrm{C}$ civarına yükseltilmesinin tanenin şeker içeriğine etkisinin olmadığını bildirmiştir. $\mathrm{Bu}$ sebeple çeşitlerin sıcaklık ve 1 şı şiddetine tepkilerinin farklılık gösterdiği anlaşılmaktadır.

Gece ile gündüz arasındaki sıcaklık fark1 artıkça $\left(12-14{ }^{\circ} \mathrm{C}\right)$ üzümde sekonder metabolitlerin birikimi yükselmekte; bundan meyvenin kalitesi, aroması ve renk oluşumu olumlu yönde etkilenmektedir (Tonietto ve Carbonneau, 2004). Artan sıcaklıklarla birlikte üzümde olgunlaşma döneminde tanede organik asit içeriği, özellikle de malik asit oranı hızlı bir şekilde azalırken, şeker konsantrasyonu, fenolik bileșikler ve potasyum oranları hızlı bir şekilde artış göstermektedir 
(Adams, 2006). Ancak, Spayd ve ark. (2002), Merlot üzüm çeşidinde yüksek gündüz sıcaklığının tane üzerine yaptığı olumsuz etkiyi serin gece sıcaklığının $\left(10-15^{\circ} \mathrm{C}\right)$ yapmadığını, $25^{\circ} \mathrm{C}$ gündüz ve $15{ }^{\circ} \mathrm{C}$ gece sicaklığında yetişen asmalarda üzümlerinin gece-gündüz sabit $15^{\circ} \mathrm{C}$ 'de yetişen üzümlere göre daha az renk gelişimine sahip olduğunu belirtmişlerdir. Benzer şekilde Crippen ve Morrison (1986a), serada gece $15{ }^{\circ} \mathrm{C}$ sabit kalmak koşuluyla, gündüz sıcaklığ $20{ }^{\circ} \mathrm{C}$ 'de yetişen Cabernet Sauvignon üzüm çeşidine ait asmalarda tane rengi gelişiminin $30{ }^{\circ} \mathrm{C}$ 'de yetişenlere göre daha iyi olduğunu tespit etmişlerdir.

Işık ve sıcaklık tanenin antosiyanin içeriğini ve miktarını etkilemektedir. Bu etkileşimde 1şı̆̆ 1 ve sıcaklığı birbirinden ayırt etmek oldukça güçtür (Bergqvist ve ark., 2001). Sıcaklık da tıpkı 1şık gibi üzümlerde renklenme üzerine etki etmektedir. Cardinal, Pinot Noir ve Tokay üzüm çeşitlerinde olgunlaşma süresince $15{ }^{\circ} \mathrm{C}$ 'lik gün sıcaklığı renk gelişimini artırırken, $35{ }^{\circ} \mathrm{C}^{\prime}$ lik gün sıcaklığg 1 antosiyanin oluşumunu azaltmış veya tamamen engellemiştir (Kliewer ve Torres, 1972). Cabernet Sauvignon üzüm çeşidinde yüksek sıcaklığın (35 $\left.{ }^{\circ} \mathrm{C}\right)$ toplam antosiyanin kontrasyonunu kontrole göre $\left(25^{\circ} \mathrm{C}\right)$ yarı yarıya azalttığ (Mori ve ark., 2007). Bununla birlikte güneş gören tanelerde gölgedekilere göre şekerler, antosiyaninler ve toplam fenolikler daha yüksek; titre edilebilir asitlik ve $\mathrm{pH}$ ise daha düşük olarak gerçekleşmektedir (Kliewer, 1977; Reynolds ve ark., 1986). Antosiyanin sentezi için optimum gün sıcaklığının 25-30 ${ }^{\circ} \mathrm{C}$ arasında olduğu, ancak 30$35^{\circ} \mathrm{C}$ 'nin üzerinde antosiyanin sentezi gerilediği bildirilmiştir (Spayd ve ark., 2002; Gonzáles Neves, 2005). Nitekim, Price ve ark. (1995), güneş 1şığının Pinot Noir üzüm tanelerinde toplam fenol konsantrasyonunu artırırken, antosiyanin içeriğine etkisi bulunmadığını belirtilmiştir. Benzer biçimde Chorti ve ark. (2010); yüksek 1şık şiddetine maruz bırakılan Nebbiolo çeşidinde salkımlarda güneş yanıklığının meydana geldiğini, yüksek ışığın suda çözünebilir kuru madde (SÇKM) ve antosiyanin birikimi üzerine bir etkisinin bulunmadığını bildirmişlerdir. Ollat ve ark. (2002) ise asmanın vejetatif gelişimi boyunca iklim değişikliklerine bağlı olarak artan sicaklıkların etkisiyle meyve bileşenlerinde potasyum oranı ve şırada $\mathrm{pH}$ düzeyinin arttığını ortaya koymuşlardır.

\subsection{Sıcaklığın fenoloji üzerine etkisi}

Fenoloji, asmada gözlerde uyanma, çiçeklenme, ben düşme, olgunlaşma ve yaprak dökümü gibi olayların, iklim faktörlerinin etkisi altında dönemsel olarak incelenmesi ve bu olayların iklim faktörleri ile ilişkilendirilmesidir.
Tomurcukların uyanması günlük ortalama sıcaklıkların $10{ }^{\circ} C^{\prime}$ ye ulaşmasıyla gerçekleşir. Asmada çiçeklenme ise, iklim, üzüm çeşidi, yıl, gün uzunluğu ve günlük ortalama sicaklıklardan etkilenmektedir. Asmalar $15.6{ }^{\circ} \mathrm{C}$ 'nin altında çok az çiçek açarken, sicaklılar 18.3 ile $21.1{ }^{\circ} \mathrm{C}^{\prime}$ ye ulaştığında çiçeklenme hızla artmaktadır (Winkler ve ark., 1974). Asmada çiçeklenme serin iklim koşullarında yaklaşık 2 hafta sürebilir ve sıcaklık $18.3{ }^{\circ} \mathrm{C}$ altında olduğu sürece çiçeklenme yavaş seyredecektir. Ancak sicaklık 29-35 ${ }^{\circ} \mathrm{C}$ olduğunda ise çiçeklenme periyodu hızlanacaktır. Sıcaklığın $18.3{ }^{\circ} \mathrm{C}$ 'nin altında olması dolayısıyla polen tüpü gelişimi, döllenme ve meyve tutumu oldukça azalmaktadır. Polen çimlenmesi ve çim borusunun gelişimi için optimum sıcaklık aralığı 26.7-32.2 ${ }^{\circ} \mathrm{C}$ olarak bildirilmiştir. Sıcaklık $15.6{ }^{\circ} \mathrm{C}$ 'nin altına ya da $37.8{ }^{\circ} \mathrm{C}$ 'nin üstüne çıktığında tane tutumu oldukça azalmaktadır (Dokoozlian, 2000). İdealinden daha sicak olan bir ortamda, bitki fenolojik aşamalardan daha hızlı geçecek ve daha erken olgunlaşma ve muhtemelen daha yüksek bir şeker olgunluğu sonucunu doğuracaktır (Jones, 2007).

İklim faktörleri tane tutumu üzerine oldukça etkilidir. Sıcaklık hücre bölünmesini ve hücre büyümesini etkiler. Tane büyümesi için optimum sicaklık 20-25 ${ }^{\circ} \mathrm{C}$ arasında olduğu, sicaklık 35 ${ }^{\circ} \mathrm{C}$ 'nin üzerine çıktığında büyüme hızı ve tane iriliği azalmaktadır. Sıcaklığa bağlı olarak, düşük sicaklıklar olgunlaşmayı geciktirdiği gibi, ben düşmeden sonraki artan yüksek sicaklıklarda benzer etkiler meydana getirebilmektedir (Dokoozlian, 2000).

İklim değişimi ile artan ortalama sıcaklıklar, pek çok bağ bölgesinde asmada fenolojik dönemler üzerine etki etmiştir. Merlot üzüm çeşidinde, y1llara göre artan sicaklıkların tomurcukların uyanması, çiçeklenme ve meyve olgunlaşma zamanlarını erkene aldığı (Jackson ve Lombard, 1993), Fransa'da Alsace bölgesinde, Almanya Baden'de ortalama sicaklıkların yükselmesi olgunlaşmayı 2 hafta daha erkene aldığı belirtilmiştir (Duchene ve Schneider, 2005; Sigler, 2008).

\section{Işı̆̆ın Asmanın Büyüme ve Gelişimi Üzerine Etkisi}

Işık bitkilerin fizyolojik olaylarına yaptığ yanında, morfolojik olarak organların şekline, biyolojik olarak çiçek organlarının oluşmasına ve çiçeklenmesine de etki etmektedir. Işık şiddetinin artması bitkilerde bodurlaşmanın, tüylenmenin ve antosiyanin gibi renk pigmentlerinin oluşumunun artmasına neden olur. Güneş 1şı̆̆ 1 , bağcılı̆̆ etkileyen en önemli iklim faktörlerden birisidir. 
Güneşlenme derecesi ve güneşlenme süresi üzümün şeker, asitlilik, renk, aroma ve olgunlaşma gibi pek çok özelliği üzerinde belirleyici olur. Bitkiler maksimum fotosentez yapabilmeleri için belirli miktarda 1şığa ihtiyaç duyarlar. Işık fotosentez için gerekli bütün enerjiyi sağladığından net asimilasyonu etkileyen en önemli faktördür. Bitkilerin, kimyasal bağ enerjisini organik madde yapımında yani fotosentezde kullanabilmesi için bitkinin taç kısmı tarafından 1şı̆̆ 1 kesmesi ve bu kesilen 1 şı enerjisini kimyasal enerjiye dönüştürebilme yeteneğinin yani 1şık kullanım etkinliğinin fazla olması gerekir (Hay ve Walker, 1989).

Bitki gelişimi için 1ş1k kadar kalitesi de önemlidir ve bitkiler optimum büyüme için bazı dalga boylarında 1şı̆̆a ihtiyaç duyarlar. Güneş 1şığının gözle görülebilen orta dalga boylu ışınları bitkilerde fotosentez başta olmak üzere temel fizyolojik ve biyokimyasal olayları yönlendirirler. Asma yaprağı güneş 1 şığı absorbe etmekte oldukça etkili olup, genel olarak maksimum fotosentez gereksinimini karşılayabilmek için tam güneş 1şığının \% 30 ile 40's kadar $\left(\geq 800 \mu \mathrm{mol} . \mathrm{m}^{-2} \mathrm{~s}^{-1}\right)$ 1şı̆̆a ihtiyaç duyarlar (Smart, 1988; Keller ve ark., 1998; Keller ve Hrazdina, 1998). Yapraklar fotosentezde mavi $(430 \mathrm{~nm})$ ve kırmızı $(660 \mathrm{~nm})$ görünür spektrum aralığındaki 1şığı absorbe ederler (Curran, 1980). Fotosentetik aktif radyasyon (PAR) bitkilerin fotosentezde kullandığı spektrum aralığıdır ve bu aralık görünür 1şığın 400'den 700 nm'ye kadarki kısmını oluşturmaktadır. Bitkiye gelen PAR'ın $\quad \% 85$ 'inden fazlası asmanın taç kısmının dış katmanı tarafından emildiği (Smart ve ark., 1985), geriye kalan \% 10-15'lik k1smın ise yapraklar tarafindan atmosfere yansıtıldığ belirtilmektedir (Smart, 1984). Tacın yapıs1 asmanın dış yaprakları tarafından yakalanan 1 şık miktarını belirler. Tacın iç kısımlarında 1 şı kalitesi de önemli ölçüde değişim gösterir. Yapraklar tarafından 1şık kesimi, 1şı̆̆ı̆ asmanın tacı içerisine doğrudan ya da sızmasıyla olmaktadır. Yapraklar tarafından kesilen 1şı̆̆ın miktarı fotosentez üretiminde tacın iç kısımlara giren yada sızan 1şı̆̆a göre daha etkili olduğu belirtilmiştir (Smart ve ark., 1988).

Işık şiddetinin belli dereceye kadar artışı, fotosentez hızını doğrusal olarak artırmaktadır. Ancak belli bir değeri aşan 1 şı şiddetinden sonra bazı bitkilerde fotosentez hızını artırmak yerine azalttı̆̆1 görülmüştür. Bunun yanı sıra, yaprakların absorbe ettiği ışı şiddeti belli bir sınırı aşarsa, sistemde kullanılabilecek sayıdan daha fazla klorofil molekülünün uyarılması söz konusudur (Vardar ve Güven, 1996). Düşük sıcaklık yüksek 1şı yoğunluğu ile birleştiğinde fotoinhibitasyona neden olmaktadır (Somersalo ve Krause, 1989;
Huner ve ark., 1993). Fotoinhibisyon, bitkilerin gelişmesi ve yaşaması için gerekli olandan daha yüksek bir ışık yoğunluğuna maruz kaldıklarında fotosentezde verim kaybı olarak tanımlanmaktadır (Maxwell ve Johnson, 2000). Işık yoğunluğunun bitkinin istediğinden fazla olması sicaklıkla bağlantılı olarak sürgün boylarının kısalmasına, bodurlaşmaya, çiçek tomurcuğu oluşumunun engellenmesine, yapraklarda sertleşme ve tüylenmeye, küçük yaprağa, çok gelişmiş kök sistemi oluşumuna ve meyve ve yaprakları tüketilen türlerde rengin açılmasına neden olur. Aksine gölgenin asmanın morfolojisini ve üretkenliğinin değiştirdiği, özgül yaprak ağırlığını, yaprakların çözünebilir karbonhidrat-nişasta içeriğini, toplam yaprak alanı, budama odunu ağırlığını, verim ve SÇKM'yi azalttı̆̆ belirtilmiştir (Vardar, 1975; Atherton ve Haris, 1986; Eriş, 1990; Uzun, 1996).

Genel olarak 1şık yoğunluğunun azalması sürgünlerde boy uzamasına, cılızlaşmaya ve gevrekleşmeye, fotosentezin azalması nedeniyle yaprak alanında azalmaya, yapraklarda sararma solma ile yaprak dökümüne rastlanmaktadır. Işık şiddetinin azalması ise bitkide hücre ve bitki boyunun uzamasına, cılızlaşmasına, sararmasına ve beyazlamasına yani etiolleşmesine neden olur. Ayrıca 1şık azlığı renklenmeyi geciktirmekte ve tat için gerekli aromatik madde oluşumunu yavaşlatmaktadır (Günay, 1982; Eriş, 1990; Cartechini ve Palliotti, 1995). Rives (2000), ormanlarda kendiliğinden yetişen yabani asmalarda (Vitis rupestris) göllenen sürgünlerin doğrusal olarak büyüdüğü, dikine geliştiği, boğum aralarının uzun ve yaprak lobunun geniş olduğu belirtmiş, güneş 1 şı ğ 1 alan sürgünlerin daha kısa boğum arası ve çok daha fazla küçük yapılı yapraklara sahip olduklarını tespit etmiştir. Köse (2006), düşük 1şık ve yüksek sıcaklık şartlarının tüpte yetiştirilen asma fidanlarında, sürgün uzunluğu, ortalama yaprak alanı ve boğum arası uzunlukların artmasına yol açtığını bildirmiştir.

McArtney ve Ferree (1999), \% 80 gölgelenen asma bitkilerinde kök kuru ağırlığının Seyval çeşidinde \% 47, De Chaunac çeşidinde \% 51 oranında azaldığı bildirmiştir. Keller ve Koblet (1995), iki farlı 1şı şiddetine (çiçeklenmeden itibaren 20 gün süre ile 30 ve $140 \mu \mathrm{mol} \mathrm{m} \mathrm{m}^{-2}$ PAR) maruz birakilan asmalarda budama odunu ağırlığı bakımından asmalar arasında fark bulunmadığını, ancak düşük 1şığın bütün bitki organlarında kuru ağırlığın azaldığını tespit etmişlerdir. McArtney ve Ferree (1999), Seyval ve De Chaunac üzüm çeşitlerinde yaptıkları araştırmada gölgelemenin her iki çeşitte de toplam bitki kuru ağırlığını azalttığını belirlemişlerdir. 
Birçok bitki türünde özgül yaprak alanı sıcaklıkla doğru orantılı ve 1şıkla ters orantılı olarak değişmektedir (Charles-Edwards ve ark., 1986). Gölgeleme farklı türlerdeki bitkilerde bitki kuru ağırlığının azalmasına, karbonhidrat seviyesinin ve fotosentez hızının azalmasına neden olmaktadır (Uzun, 1996). Gölgelenen asmalarda yaprak, sürgün, gövde, kök ve tüm bitki kuru ağırlığı gölgeleme oranındaki artışa bağlı olarak azalma göstermektedir (Grant ve Ryugo, 1984; Rom ve Ferree, 1986). Bindi ve ark. (1997) Sangiovese üzüm çeşidinde, kesilen 1şıkla kuru madde birikiminin doğrusal olarak arttığını tespit etmişlerdir. Araştırmacılar, tane tutumundan sonra yoğun biçimde gölgelenen tanelerin 1 şık görenlere göre oldukça küçük kaldığı, bu durumun 1şı̆̆ın hücre bölünmesini ve gelişimini etkilemesinden kaynaklandığgnı belirtmişlerdir.

Düşük 1şık, tane büyüme hızının azalmasına neden olurken, şeker ve fenolik bileşiklerin azalmasına, asitliğin artmasına yol açmaktadır (Smart ve ark., 1988). Genel olarak düşük 1şı̆̆ın asmada büyüme ve gelişime üzerine etkileri; ana sürgün uzamasını azaltması, yan sürgün uzamasını arttırmas1, meyve tutumunu ve meyve rengi gelişimini azaltması, olgunlaşmayı geciktirmesi, asit yıkımını azaltması, çiçek tomurcuğu oluşumunu azaltması, boğum arası uzunluğunu arttırması, hastalık riskini ve böcek popülasyonunu arttırması şeklinde ortaya çıkmaktadır (Morgan ve ark., 1985; Dry, 2000; Petrie ve ark., 2003).

\subsection{Işı̆̆ın salkım ve tane içeriği üzerine etkisi}

Güneş 1şı̆̆1 asmanın büyümesi, tanenin olgunlaşması ve bağlarda hastalık gelişimi üzerine geniş etkide bulunmaktadır (Bois ve ark., 2008). Renkli üzüm çeşitlerinde salkımların gölgelenmesi, tanenin renklenmesi, antosiyanin konsantrasyonu ve çözünebilir şekerleri azaltırken, titre edilebilir asitliği artırmaktadır (Francesco ve ark., 1994). Üzümlerin olgunlaşması süresince özellikle yeterli bir güneşlenme gerekmektedir (Manica ve Pommer, 2006). Pek çok bitkideki gibi asmada da 1şı̆̆ın kullanılabilirliği kuru madde üretimini artırmaktadır. Bitkilerde kuru madde birikimi genellikle bitki tarafindan kesilen toplam PAR ile belirli bir noktaya kadar doğru orantılı olarak artmaktadır (Monteith, 1977; Bindi ve ark., 1997). Vanden Heuvel ve ark. (2004), tarafindan yapılan bir araştırmada asmanın yaprak yaş ağırlığı, hacmi, yoğunluğu ve yaprak kalınlığ artan gölgeleme seviyesiyle azalma göstermiştir.

Çeşitli ortam faktörlerinin, birbirleriyle etkileşim içinde ve oldukça karmaşık bir şekilde, fotosentez hızında etken olduğu bilinmektedir. Pek çok araştırmacı doğal koşullarda fotosentez aktivitesi ve tane olgunlaşması üzerine 1 şı ve sıcaklığın etkilerini ayırmanın zorlukları hakkında bilgi vermektedir (Crippen ve Morrison, 1986b; Schultz ve ark., 1996; Bergqvist ve ark., 2001). Işık, asma dahil olmak üzere birçok meyvede büyüme ve meyvenin bileşimini etkilemektedir (Shahak ve ark., 2004). Ben düşme sonrasında üzüm kalitesi üzerine etkili olan ana faktörün 1şıklanma şartlarına bağlı olduğu bildirilmiştir (Keller ve Hrazdina, 1998). Smart ve ark. (1988) gölgeleme uygulamalarının olgunlaşma periyodu, meyve olgunlaşması ve üzüm kalitesini etkilediğini ifade etmişlerdir. Kliewer ve ark. (1967), 1şıklanmayı azaltan gölgeleme uygulamalarının meyve olgunlaşmasını 1 ile 5 haftaya kadar geciktirdiğini bildirmektedirler.

Işıklanmanın azaltılması şeker ve organik asit konsantrasyonunu etkilemekte ve meyve olgunlaşmasını geciktirmektedir (Kliewer ve ark., 1967; Kliewer ve Antcliff, 1970). Güneş 1şı̆̆ına aşırı maruz kalmanın tanelerin antosiyanin içeriğini ve şeker konsantrasyonunu azaltabileceği bildirilmiştir (Bergqvist ve ark., 2001). Güneş 1şı̆̆ alan meyvelerde genellikle çözünebilir kuru madde, antosiyaninler ve fenolikler daha yüksekken, gölgelenen yada 1 şı almayan meyvelerde titre edilebilir asitlik, $\mathrm{pH}$ ve tane ağırlığın daha düşük bulunmuştur (Crippen ve Morrison, 1986a ve 1986b; Reynolds ve ark., 1986; Mabrouk ve Sinoquet, 1998). Jackson ve Lombard (1993)'ın yaptıkları araştırmada, çiçeklerin açılması ile ben düşme dönemleri arasında yapılan yaprak alma işleminin Cabernet Sauvignon üzüm çeşidinin tane kabuğundaki fenolik bileşikler ile antosiyaninleri $\operatorname{arttırdığ~}{ }_{1}$ tespit edilmiştir.

Işık ve sıcaklık çiçek salkımı gelişimini, çiçek oluşumunu ve verimliliği doğrudan etkilemektedir (Williams, 2000; Sanchez ve Dokoozlian, 2005). Asmalarda kış gözlerinin verimliliği üzerine 1 şık sıcaklıktan bağımsız biçimde etki etmektedir. Sicaklığın $25^{\circ} \mathrm{C}$ 'de sabit tutulduğu şartlarda, farklı 1şık yoğunluklarında yetiştirilen asmalarda 1 şık yoğunluğu arttıkça çiçek salkımı sayısının da arttığ tespit edilmiştir (Buttrose, 1970). Asmalarda gölgeleme genel olarak verimliliği azaltmaktadır. Düşük 1şık şiddetinin çiçek tomurcuğu oluşumunu azalttığ1 (Kobayashi ve ark., 1966; Buttrose, 1969a, 1969b, 1974), Sultani çekirdeksiz üzüm çeşidinde çiçek tomurcuğu oluşumu süresinde günde ortalama 10 saatlik bir güneşlenme süresine ihtiyaç olduğu bildirilmiştir (Baldwin, 1964). Bunun yanı sıra, asmada çiçek tomurcuğu oluşumu için yüksek sıcaklığa ihtiyaç duyulduğu, yüksek sıcaklığın verimliliği arttırdığı belirtilmiştir (Alleweldt, 1963). Ancak Buttrose (1970), çeşitlerin sıcaklığa tepkilerinin farklı olduğunu, Riesling ve Shiraz üzüm çeşitlerinde morfolojik 
ayırım $20{ }^{\circ} \mathrm{C}$ 'de başlarken, İskenderiye Misketinde morfolojik ayırım için $25{ }^{\circ} \mathrm{C}$ sicaklık olması gerektiğini bildirmiştir.

\section{Sonuçlar}

Işık ve sıcaklık, bağcılığı etkileyen en önemli iklim faktörlerinden ikisidir. Sicaklık, bir ekolojide bağcılık yapılıp yapılamayacağını belirleyen önemli parametrelerin başında gelir. Sicaklık bağ bölgelerinin belirlenmesinin yanı sıra, asmada fizyolojik ve biyokimyasal pek çok olayda belirleyici rol oynar. Vegetasyon dönemi boyunca ortalama $20-30{ }^{\circ} \mathrm{C}$ arasındaki ortalama sicaklıklar asmada optimum fotosentezi sağlamaktadır. Güneş 1şığının yoğunluğu ve güneşlenme süresi asmanın fotosentez, şeker, asitlilik, renk, aroma ve olgunlaşma gibi pek çok özelliği üzerinde belirleyici etkide bulunur. Işık bitkiye fotosentezle enerjiyi sağladığından net asimilasyonu etkileyen en önemli faktördür. Işık yoğunluğunun azlığ1 kadar fazlalığı da fotosentezde sinırlayıcı etki yapmaktadır. Asmada etkin bir fotosentez üretimi için optimum 1 ş1k yoğunluğu gerekmektedir. Optimum bir güneşlenme için uygun terbiye şekillerinin oluşturulması ve asmalarda taç yönetimi uygulamaları verim ve kalite üzerine olumlu etkide bulunacaktır.

\section{Kaynaklar}

Adams, D.O., 2006. Phenolics and ripening in grape berries. American Journal of Enology and Viticulture, 57: 249-256.

Ağaoğlu, Y.S., 1999. Bilimsel ve Uygulamalı Bağcılık (Asma Biyolojisi). Kavaklıdere Eğitim Yayınları 1, Ankara.

Akman, Y., Küçüködük, M., Evren, H., Öncel, I., Düzenli, S., 2000. Fotosentez (Fotorespirasyon, 4C'lu Karbon Döngüsü ve Crassulacean Asit Metabolizmas1). Kariyer Matbaacılık Ltd. Şti., Ankara.

Alleweldt, G., 1963. Einfluss von klimafaktoren auf die zahl der inflorescenzen bei reben. Wein-Wiss, 18(2): 61-70.

Alleweldt, G., 1997. Genetics of grapevine breeding. Progress in Botany, 58: 441-454.

Amerine, M.A., Winkler, A.J., 1944. Composition and quality of musts and wines of california grapes. Hilgardia, 15: 493-675.

Anonymous, 2014. Food and Agriculture Organization of the United Nations (FAO). http://faostat.fao.org/ site/567/DesktopDefault.aspx?PageID=567\#ancor (Erişim tarihi: 24.07.2014).

Atherton, J.G., Harris, G.P., 1986. Flowering. In: J.G. Atherton and J. Rudich (Eds), The Tomato Crop. Chapman And Hall, London, pp.167-200.
Baldwin, J.G., 1964. The relation between weather and fruitfulness of the Sultana vine. Aust. J. Agric. Res., 15: 920-928.

Bergqvist, J., Dokoozlian, N., Ebisuda, N., 2001. Sunlight exposure and temperature effects on berry growth and composition of Cabernet-Sauvignon and Grenache in the Central San Joaquin Valley of California. American Journal of Enology and Viticulture, 52(1): 1-7.

Bindi, M., Miglietta, F., Gozzini, B., Orlandini, S., Seghi, L., 1997. A simple model for simulation of growth and development in grapevine (Vitis vinifera L.), I. Model description. Vitis, 36(2): 67-71.

Blanco-Ward, D., Queijeiro, J.G., Jones, G.V., 2007. Spatial climate variability and viticulture in the Miño River Valley of Spain. Vitis, 46(2): 63-70.

Bois, B., Wald, L., Pieri, P., Van Leeuwen, C., Commagnac, L., Chery, P., Christen, M., Gaudillère J.P., Saur, E., 2008. Estimating spatial and temporal variations in solarradiation within bordeaux winegrowing region using remotely sensed data. Journal International des Sciences de la Vigne et du Vin, 42: 15-25

Butrosse, M.S., 1970. Fruitfulness in grapevines: the response of different cultivars to light, temperature and day length. Vitis, 9: 121-125.

Buttrose, M.S., 1969a. Fruitfulness in grapevines: Effects of light intensity and temperature. Bot. Gaz., 30: 166-73.

Buttrose, M.S., 1969b. Vegetative growth of grapevine varieties under controlled temperature and light intensity. Vitis, 8: 280-285.

Buttrose, M.S., 1974. Climatic factors and fruitfulness in grapevines. Hort. Abstr., 44: 319-25.

Cartechini, A., Palliotti, A., 1995. Effect of shading on vine morphology and productivity and leaf gas exchange characterictics in grapevines in the field. Amer. J. Enol. Viticultu., 46: 227-235.

Charles-Edwards, A.D., Doley, D., Rimmingon, G.M., 1986. Modelling Plant Growth and Development, Academic Press., Sydney, Australia.

Chorti, E., Guidoni, S., Ferrandino, A., Novello, V., 2010. Effect of different cluster sunlight exposure levels on ripening and anthocyanin accumulation in Nebbiolo grapes. American Journal of Enology and Viticulture, 61(1): 23-30.

Crippen, D.D., Morrison, J.C., 1986a. The effects of sun exposure on the compositional development of Cabernet Sauvignon berries. American Journal of Enology and Viticulture, 37: 235-242.

Crippen, D.D., Morrison, J.C., 1986b. The effects of sun exposure on the phenolic content of Cabernet Sauvignon berries during development. American Journal of Enology and Viticulture, 37: 243-247.

Curran, P., 1980. Multispectral remote sensing of vegetation amount. Progress in Physical Geography, 4(3): 315-341.

Çelik, S., 2007. Bağcılık (Ampeloloji-I). Anadolu Matbaa Ambalaj San. ve Tic. Ltd. Şti., Cilt I Genişletilmiş 2. Bask1, Tekirdağ. 
Dokoozlian, N., 2000. Grape berry growth and development, In: Raisin Production Manual. University of California, Agricultural and Natural Resources Publication 3393, Oakland, CA.

Dookozlian, N.K., Kliewer, W.M., 1996. Influence of light on grape berry growth and composition varieties during development. Journal of the American Society for Horticultural Science, 121: 233-236.

Dry, P.R., 2000. Canopy management for fruitfulness. Australian Journal of Enology and Viticulture, 6: 109-115.

Duchene, E., Schneider, C., 2005. Grapevine and climatic changes: A glance at the situation in Alsace. Agronomie, 25(1): 93-99.

During, H., 1994. Photosynthesis of ungrafted and grafted grapevines: Effects of rootstock genotype and plant age. Am. J. Enol. Vitic., 45(3): 297-299.

Eriş, A., 1990. Bahçe Bitkileri Fizyolojisi. Uludağ Üniversitesi Ders Notları, No: 11, Bursa.

Ferrini, F., Mattii, G.B., Nicese, F.P., 1995. Effect of temperature on key physiological responses of grapevine leaf. Am. J. Enol. Vitic., 46: 375-379.

Francesco, I., Massimo, B., Fulvio, M., Attilio, S. 1994. Differential effects of canopy manipulation and shading of Vitis vinifera L. cv. Cabernet Sauvignon, I. Composition of grape berries. Vitic. Enol. Sci., 49: 220-225.

Gladstones, J., 1992. Viticulture and environment. Winetitles, Adelaide, Australia.

Gonzales Neves, G., 2005. Módulo Materia Prima. Clases de la Maestría de Viticultura \& Enología, Ciclo 2004/2005. FCA UN Cuyo, INTA, INV.

Grant, J.A., Ryugo, K., 1984. Influence of withincanopy shading on net photosynthetic rate, stomatal conductanse, and chloropphyll content of kiwifruit leaves. Hort. Science, 19: 834-836.

Greer, D.H., Weston, C., 2010. Heat stress affects flowering, berry growth, sugar accumulation and photosynthesis of Vitis vinifera cv. Semillon grapevines grown in a controlled environment. Functional Plant Biology, 37: 206-214.

Günay, A., 1982. Genel Sebze Yetiştiriciliği. Ankara Üniversitesi Ziraat Fakültesi Bahçe Bitkileri Bölümü, Çă̆ Matbaası, Cilt I, Ankara.

Happ, E., 1999. Indices for exploring the relationship between temperature and grape and wine flavour. Australian \& New Zealand Wine Industry Journal, 14: 68-76.

Hay, R.K.M., Walker, A.J., 1989. An Introduction to Do Physiology of Crop Yield. Longman Scientific and Technical, England.

Huglin, P., 1978. Nouveau mode d'évaluation des possibilités héliothermiques d'un milieu viticole. In: Proc Symp Int sur l'ecologie de la Vigne. Ministère de l'Agriculture et de l'Industrie Alimentaire. Contança, pp: 89-98.

Huner, N.P.A., Oquist, G., Hurry, VM., Krol, M., Falk, S., Griffith, M., 1993. Photosynthesis, photoinhibition and low temperature acclimation in cold tolerant plants. Photosynth Res., 37: 19-39.

Hunter, J.J., Bonnardot, V., 2011. Suitability of some climatic parameters for grapevine cultivation in South Africa, with focus on key physiological processes. S. Afr. J. Enol. Vitic, 32(1): 137-154.

Irimia, L., Patriche, C.V., Quénol, H., 2013. Viticultural zoning: A comparative study regarding the accuracy of different approaches in vineyards climate suitability assessment. Cercetari Agronomice in Moldova, 46(3): 95-106.

Jackson, D.I., Lombard, P.B., 1993. Environmental management practices affecting grape composition and wine quality a review. Am. J. Enol. Vitic., 44: 409-430.

Jones, G.V., 2007. Climate change: Observations, projections, and general implications for viticulture and wine production. Pract. Winery Vineyard, 28(2): 44-64.

Jones, G.V., Reid, R., Vilks, A., 2012. Climate, Grapes and Wine: Structure and Suitability in a Variable and Changing Climate. Pp.109-133 in The Geography of Wine: Regions, Terrior and Techniques, (Ed.): Dougherty, P. Springer Pres.

Kacar, B., 1989. Bitki Fizyolojisi. Ankara Üniversitesi Ziraat Fakültesi Yayınları: 1153, Ders Kitabı: 323, Ankara.

Keller, M., Arnink, K.J., Hrazdina, G., 1998. Interaction of nitrogen availability during bloom and light intensity during veraison: I. Effects on grapevine growth, fruit develop-ment, and ripening. American Journal of Enology and Viticulture. 49: 333-340.

Keller, M., Hrazdina, G., 1998. Interaction of nitrogen availability during bloom and light intensity during veraison: II. Effects on anthocyanin and phenolic development during grape ripening. American Journal of Enology and Viticulture, 49: 341-349.

Keller, M., Koblet, W., 1995. Dry matter and leaf area partioning, bud fertility and second season growth of Vitis vinifera L.: Responses to nitrogen supply and limiting irradiance. Vitis, (34): 77-83.

Kliewer, M., Lider, L.A., Schultz, H.B., 1967. Influence of artificial shading of vineyards on the concentration of sugar and organic acid in grapes. Am. J. Enol. Vitic., 18(2): 78-86.

Kliewer, W.M., 1977. Influence of temperature, solar radiation, and nitrogen on coloration and composition of 'Emperor' grapes. Amer. J.Enol. Viticult., 28: 96-103.

Kliewer, W.M., Antcliff, A.J., 1970. Influence of defoliation, leaf darkening and cluster shading on the growth and composition of Sultana grapes. American Journal of Enology Viticulture, 21: 26-36.

Kliewer, W.M., Torres, R.E., 1972. Effect of controlled day and night temperatures on grape coloration. American Journal ofEnology and Viticulture, 23: 7177.

Kobayashi, A., Sugiura, A., Watanabe, H., Yamamura, H., 1966. On the effects of day length on the 
growth and flower bud formation of grapes. Mem. Res. Inst. Food Sci., 27: 15-27.

Köse, B., 2006. Samsun ekolojik şartlarında tüplü asma fidan yetiştiriciliğinde işık ve sıcaklığın vegetatif gelişme ve fidan kalitesi üzerine etkisinin saptanmas1. Doktora tezi, Ondokuz May1s Üniversitesi Fen Bilimleri Enstitüsü Bahçe Bitkileri Ana Bilim Dalı, Samsun.

Kriedemann, P.E., 1968. Photosynthesis in vine leaves as a function of light intensity, temperature, and leaf age. Vitis, 7: 213-220.

Lebon, E., Pellegrino, A., Louarn, G., Lecoeur, J., 2006. Branch development controls leaf area dynamics in grapevine (Vitis vinifera) growing in drying soil. Annals of Botany, 98: 175-185.

Mabrouk, H., Sinoquet, H., 1998. Indices of light microclimate and canopy structure of grapevines determined by 3D digitising and image analysis, and their relationship to grape quality. Australian Journal of Grape and Wine Research, 4(1): 2-13.

Manica, I., Pommer, C.V., 2006. Uva: Do plantio a produção pós-colheita e mercado. Cinco Continentes, Porto Alegre.

Maxwell, K., Johnson, G.N., 2000. Chlorophyll fluorescence a practical guide. Journal of Experimental Botany, 51(345): 659-668.

McArtney, S.J., Ferree, D.C., 1999. Root and cane pruning affect vegetative development, fruiting and dry-matter accumulation of grapevines. Hort. Science, 34(4): 617-621.

Monteith, J.L., 1977. Climate and the efficiency of crop production in Britain. Physiological Translocations of the Royal Society of London, 281: 277-294.

Morgan, D.C., Stanley, C.J., Warrington, I.J., 1985. The effect of simulated daylight and shade-light on vegetative and reproductive growth in kiwifruit and grapevine. J. Hort. Sci., 60: 473-484.

Mori, K., Goto-Yamamoto, N., Kitayama, M., Hashizume, K., 2007. Loss of anthocyanins in redwine grape under high temperature. Journal of Experimental Botany, 58(8): 1935-1945.

Mullins, M.G., Bouquet, A., Williams, L.E., 1992. Biology of the grapevine. Cambridge Univ. Pres., Cambridge, UK.

Ollat, N., Diakou-Verdin, P., Carde, J.P., Barrieu, F., Gaudillere, J.P., Moing, A., 2002. Grape berry development: A review. J. Int. Sci. Vigne Vin., 36: 109-131.

Oraman, M.N., 1970. Bağcılık Tekniği I. Ankara Üniversitesi Ziraat Fakültesi Yayınları, No: 415, Ankara.

Öndeş, D., Çam, A., Eskioğlu, O., Öz, Ş., 2005. Türkiye'de Sicaklık ve Yağış Analizlerine Göre En Uygun Bağ Alanları. Çevre ve Orman Bakanlığı Yayınları: I, Ankara.

Petrie, P.R., Trought, M.C.T., Howell, G.S., Buchan, G.D., 2003. The effect of leaf removal and canopy height on whole-vine gas exchange and fruit development of Vitis vinifera L. Sauvignon Blanc. Functional Plant Biology, 30: 711-717.
Price, S.F., Bren, P.J., Valladao, M., Watson, B.T., 1995. Cluster sun exposure and quercetin in grapes and wine. Am. J. Enol.Vitic., 46: 187-194.

Reynolds, A.G., Pool, R.M., Mattick, L.R., 1986. Influence of cluster exposure on fruit composition and wine quality of Seyval blanc grapes. Vitis, 25: 85-96.

Rives, M., 2000. Vigour, pruning, cropping in the grapevine (Vitis vinifera L.). I. A literatüre review. INRA, EDP Sciences, Agronomic, 20: 79-91.

Rom, C.R., Ferree, D.C., 1986. The influence of fruiting and shading of spurs and shoots on spur performance. J. Am. Soc. Hortic. Sci., 111: 352-356.

Sánchez, L.A., Dokoozlian, N.K., 2005. Bud microclimate and fruitfulness in Vitis vinifera L. American Journal of Enology and Viticulture, 56(4): 319-329.

Schultz, H.R., Kiefer, W., Gruppe, W., 1996. Photosynthetic duration, carboxylation efficiency and stomatal limitation of sun and shadeleaves of different ages in field-grown grapevine (Vitis vinifera L.). Vitis, 35(4): 169-176.

Schwartz, M.D., 2003. Phenology: An intergative environmental science. Kluwer Academic Publishers, Dordrecht, Boston, London.

Shahak, Y., Gussakovsky, E.E., Gal, E., Ganelevin, R., 2004. Colour nets: Crop protection and light-quality manipulation in one technology. Acto Horticulturae, 659: 143-151.

Sigler, J., 2008. In den Zeiten des Klimawandels: Von der Süßreserve zur Sauerreserve? Der Badische Winzer, 33: 21-25.

Smart, R.E., 1984. Some aspects of climate, canopy microclimate, vine physiology, and wine quality. Proceedings of the First International Cool Climate Viticulture and Enology Symposium, Oregon State University, Corvallis, pp. 1-19.

Smart, R.E., 1988. Shoot Spacing and canopy light microclimate. American Journal of Enology and Viticulture, 39: 325-333.

Smart, R.E., Robinson, J.B., Due, G.R., Brian, C.J., 1985. Canopy microclimate for the cultivar Shiraz, I. Definition of canopy microclimate. Vitis, 24: 17-31.

Smart, R.E., Smith, S.M., Winchester, R.V., 1988. Light quality and quantity effects on fruit ripening for Cabernet Sauvignon. American Journal of Enology and Viticulture, 39: 250-258.

Soar, C.J., Collins, M.J., Sadras, V.O., 2009. Irrigated Shiraz vines (Vitis vinifera) upregulate gas exchange and maintain berry growth in response to short spells of high maximum temperature in the field. Funct. Plant Biol., 36: 801-814.

Somersalo, S., Krause, G.H., 1989. Photoinhibition at chilling temperature: Fluorescence characteristics of unhardened and cold-acclimated spinach leaves. Planta, 177: 409-416.

Spayd, S.E., Tarara, J.M., Mee, D.L., Ferguson, J.C., 2002. Separation of sunlight and temperature effects on the composition of Vitis vinifera cv. Merlot 
berries. American Journal of Enology and Viticulture, 53(3): 171-182.

Tonietto, J., Carbonneau, A., 2004. A multicriteria climatic classification system for grape-growing regions worldwide. Agricultural and Forest Meteorology, 124(1): 81-97.

Uzun, S., 1996. The quantitative effects of temperature and light environment on the growth, development and yield of tomato and aubergine. Unpublished $\mathrm{PhD}$ thesis, The Univ. of Reading, England.

Van Leeuwen, C., Friant, P., Choné, X., Tregoat, O., Koundouras, S., Dubourdieu, D., 2004. Influence of climate, soil and cultivar on terroir. Am. J. Enol. Vitic., 55: 207-217.

Vanden Heuvel, J.E., Leonardos, E.D., Proctor, J.T.A., Fisher, K.H., Sullivan, J.A., 2004. Shading affects morphology, dry-matter partioning, and photosynthetic response of greenhouse-grown "Chardonnay" grapevines. Hort. Science, 39(1): 6570.

Vardar, Y., 1975. Bitki Fizyolojisi Dersleri II (Bitkilerin Büyüme ve Gelişme Olayları). Ege Üniversitesi Fen Fakültesi Kitapları Serisi No 69, Bornova-İzmir.

Vardar, Y., Güven, A., 1996. Bitki Fizyolojisine Giriş. Barış Yayınları, Fakülteler Kitapevi, İzmir.

Williams, L.E., 2000. Bud development and fruitfulness of grapevines. In Raisin Production Manual, L.P. Christiansen (Ed.) University of California Division of Agriculture and Natural Resources Publication 3393, Oakland, pp. 24-29.

Winkler, A.J., Cook, J.A., Kliewer, W.M., Lider, L.A. 1974. General Viticulture. University of California Press., Berkeley, California. 